\title{
Excessive nerve growth factor impairs bidirectional communication between the oocyte and cumulus cells resulting in reduced oocyte competence
}

\author{
Yiwen Zhai ${ }^{1,2}$, Guidong Yao ${ }^{3}$, Faiza Rao ${ }^{1,2}$, Yong Wang ${ }^{1,2}$, Xiaoyuan Song ${ }^{1,2}$ and Fei Sun ${ }^{1,2^{*}}$
}

\begin{abstract}
Background: Excessive nerve growth factor (NGF) is commonly found in the follicular fluid of patients with polycystic ovary syndrome (PCOS). Furthermore, oocytes from PCOS patients exhibit lower developmental competence. The purpose of this study was to explore the association between excessive NGF and low oocyte competence in vitro.

Methods: Excessive NGF was added to mouse cumulus oocyte complexes (COCs) cultured in vitro to investigate meiotic maturation of the oocyte. After culture, mRNA expression levels of Pfkp and Ldha genes in cumulus cells (CCs) and Gdf9, Bmp15 and Fgf8 genes in oocytes, were determined by real-time quantitative polymerase chain reaction (qPCR). We also investigated the mRNA content of Pfkp and Ldha in CCs from PCOS and non-PCOS patients.

Results: Excessive NGF significantly inhibited oocyte meiotic maturation. The inhibitory effect was mediated by the NGF high-affinity receptor, NTRK1. mRNA content of Pfkp and Ldha genes in CCs was significantly reduced by excessive NGF stimulation. Moreover, the expression levels of Gdf9, Bmp15 and Fgf8 were also decreased in oocytes, and was induced by excessive NGF-stimulated CCs. In addition, lower expression levels of Pfkp and Ldha in CCs were identified in Chinese PCOS patients with excessive NGF (PCOS, $22 \pm 2.63 \mathrm{ng} / \mathrm{ml}, n=13 ;$ non-PCOS, $7.18 \pm 2.42 \mathrm{ng} / \mathrm{ml}, n=9 ; p<0$. 01 in the follicular fluid, suggesting a potential association between excessive NGF and decreased glycolysis in the CCs of women with PCOS.
\end{abstract}

Conclusions: Excessive NGF impairs bidirectional communication between oocyte and cumulus cells, which might be related to low oocyte competence.

Keywords: Polycystic ovary syndrome, NGF, Oocyte-derived paracrine factors, Bidirectional communication, Glycolysis

\section{Background}

Nerve growth factor (NGF) is a member of the neurotrophin family [1]. While originally reported to exert functionality in the nervous system, NGF has been found to play important roles in the reproductive system $[1,2]$. Various types of cells in the mammalian ovary, including theca cells, granulosa cells and cumulus cells (CCs) have been reported to produce NGF [1, 3]. Consistent with its local production in the ovary, NGF is

\footnotetext{
* Correspondence: feisun@ustc.edu.cn

'School of Life Sciences, University of Science and Technology of China, Hefei, Anhui, People's Republic of China

${ }^{2}$ Hefei National Laboratory for Physical Sciences at Microscale, Hefei, Anhui, People's Republic of China

Full list of author information is available at the end of the article
}

also known to participate in the regulation of folliculogenesis and ovulation $[1,2,4-6]$. The deficiency of NGF in mice is known to lead to a significant reduction of primary and secondary follicles, implying that NGF is necessary for the preantral-follicle stage $[2,4]$. Furthermore, the preovulatory increase of NGF in the follicular fluid of rats, golden hamsters and sheep indicated the involvement of NGF in ovulation [1,5]. Other studies reported that single nucleotide polymorphism of the NGF gene in goats might be associated with litter size, which also emphasized the importance of NGF in reproduction [7, 8]. NGF has also been reported to play roles in oocyte maturation [9]. The addition of NGF to the in vitro medium promoted the resumption of 
meiosis in murine oocytes [10], and improves cleavage rate in sheep embryos [11]. However, NGF failed to enhance oocyte maturation and developmental competence in pigs and cows $[9,12]$. Thus, the function of NGF in the process of oocyte maturation remains rather controversial and is in need of further elucidation.

Interestingly, an increasing number of studies are providing evidence to show that NGF is associated with ovarian diseases, such as polycystic ovary syndrome (PCOS) [1, 13-15]. PCOS, heterogeneously characterized by polycystic ovaries, hyper-androgenism and chronic anovulation, is a common ovarian disease which causes infertility or sub-fertility in $6-8 \%$ of women in reproductive age [16]. The presence of excessive NGF in follicular fluid is a clinical manifestation of PCOS patients $[13,15,17]$. Research has shown that transgenic mice expressing excessive NGF exhibit PCOS-like symptoms, such as the formation of follicular cysts, hyperandrogenemia, increased granulosa cell apoptosis, reduced ovulation and fertility and perturbed reproductive and metabolic features $[13,14]$. Nevertheless, the mechanism underlying excessive NGF in the follicular fluid of patients with progressive PCOS remains unclear.

PCOS patients consistently suffer from the poor quality of oocytes $[16,18,19]$ and this represents a major cause of sub-fertility or infertility $[16,18,20]$. Although a series of extra- and intra-ovarian factors have been identified and linked to abnormal oocyte maturation [16], the underlying mechanisms still require further clarification. Bidirectional communication between oocytes and the surrounding CCs plays an essential role in oocyte maturation [21-24]. During maturation, oocytes are deficient in synthesizing glucose metabolic enzymes; they use pyruvate as an energy substrate, which is transported from companion CCs [25-27]. Glycolysis in the CCs is dominated by oocytederived paracrine factors (ODPFs) [21], of which two families have been identified: the transforming growth factor $\beta$ superfamily, including growth differentiation factor 9 (GDF9) and bone morphogenetic protein 15 (BMP15); and the fibroblast growth factor (FGF) family, including FGF8 and other members [28-30]. Deficiency of these genes in vivo, such as in $G d f 9^{-/-}$and $G d f 9^{-/} B m p 15^{-\prime}$ -mice, leads to reproductive defects [23]. The addition of BMP15 and FGF8 to in vitro cultured CCs has been shown to promote glycolysis [31]. Despite the fact that bidirectional communication is important to oocyte maturation, its role in the pathogenesis of PCOS remains undefined.

In the present study, we aimed to clarify the role of excessive NGF in the follicular fluid of PCOS patients and investigated the effect of excessive NGF on oocyte maturation in the mouse model. To mimic excessive NGF in the follicular fluid and dissect it from other microenvironmental factors, we performed in vitro culture of isolated mouse COCs in the presence of excessive NGF. We found that excessive NGF inhibited oocyte maturation in mouse COCs, and that the inhibitory effect was mediated by the bidirectional communication between oocyte and CCs. Moreover, corresponding to the observation that mRNA expression of glycolytic enzymes reduced in mouse CCs when COCs were cultured with excessive NGF, mRNA expression of glycolytic enzymes significantly reduced in CCs isolated from PCOS patients with excessive NGF in the follicular fluid. These findings revealed a potential pathogenic role of excessive NGF in the progression of PCOS by impairing oocyte maturation.

\section{Methods}

\section{Animals}

ICR mice were bred and raised in the Animal Center, University of Science and Technology of China. Mice were adapted to a 12-h light/12-h dark cycle at room temperature $\left(22-24{ }^{\circ} \mathrm{C}\right)$. All experiments involved 21-day-old female mice. The study was approved by the Institutional Review Board of the University of Science and Technology of China on the 18th May 2012 (Reference: USTCACUC1201054).

\section{Subjects}

Follicular fluid and CCs were collected from 22 Han Chinese women ( $n=9$, non-PCOS; $n=13$, PCOS) during their first cycle of in vitro fertilization (IVF) or intracytoplasmic sperm injection (ICSI) at the First Affiliated Hospital of Zhengzhou University from January 2015 to May 2015. Written informed consent was obtained from all patients and the study was approved by the Ethics Review Board of the First Affiliated Hospital of Zhengzhou University on $20^{\text {th }}$ November 2014 (Reference: 2014-LW-1217). All of the PCOS patients were selected according to the Revised 2003 Consensus on Diagnostic Criteria: Oligo- and/or Anovulation, Hyper-androgenism and Polycystic Ovary [32]. All of the non-PCOS patients had normal ovarian morphology and regular menstrual cycles with male factor infertility. Age, ratio of body weight/height, luteinizing hormone (LH), follicle stimulating hormone (FSH) and testosterone levels of both of PCOS patients and non-PCOS patients were measured and recorded.

\section{Human follicular fluid and CCs collection}

After ovarian stimulation with agonadotropin-releasing hormone agonist (Serono, Geneva, Switzerland) and recombinant FSH (Serono, Geneva, Switzerland), three or more follicles reached $17 \mathrm{mmin}$ diameter, and then 6000-10,000 IU of human chorionic gonadotropin (hCG, LizhuInc., Zhuhai, China) was administered. COCs were then retrieved from aspirated follicles $36 \mathrm{~h}$ after the hCG trigger. Follicular fluid was obtained from 
the first aspirated follicles and centrifuged at $450 \mathrm{~g}$ for $5 \mathrm{~min}$; the clear supernatant was then stored at $-80{ }^{\circ} \mathrm{C}$ for subsequent NGF assessment. CCs were collected from 9 non-PCOS patients and 5 PCOS patients who received ICSI-embryo transfer, but not IVF-embryo transfer treatment as CCs from such patients would be contaminated with human sperm.

\section{Measurement of NGF in human follicular fluid}

Follicular fluid was first treated with acid as described previously $[17,33]$ to increase measurable NGF levels. In brief, all samples were diluted 1:15,000 in Dulbecco's phosphate-buffered saline (DPBS) and treated with $1 \mathrm{~mol} / \mathrm{L}$ of $\mathrm{HCl}$ at $\mathrm{pH} 2.6$ for $30 \mathrm{~min}$. This was then neutralized by $1 \mathrm{~mol} / \mathrm{L}$ of $\mathrm{NaOH}$ to $\mathrm{pH}$ 7.6. NGF was then measured using a human $\beta$-NGF Duoset ELISA Kit (R\&D Systems, Minneapolis, USA) in accordance with the manufacturer's instructions. In brief, 96-well plates were coated with anti-NGF (human) monoclonal antibody and incubated overnight at $4{ }^{\circ} \mathrm{C}$. All washing steps were conducted 4 times with wash buffer $(360 \mu \mathrm{l} /$ well $)$. Assay plates were washed as above and incubated with blocking buffer for $2 \mathrm{~h}$ at room temperature to block non-specific binding. Follicular fluid samples (200 $\mathrm{\mu l} /$ well) and gradient standard NGF samples were added to the appropriate assay wells in duplicate and then incubated for $6 \mathrm{~h}$ at room temperature. After incubation, the plates were washed and then detection antibody was added and incubated for $2 \mathrm{~h}$ at room temperature. Afterwards, plates were washed and labeled with streptavidinHRP for $20 \mathrm{~min}$ in the dark. Then, substrate solution and stop solution were added into the plates for absorbance measurement. The concentration follicular fluid was calculated using a standard curve.

\section{Reagents and medium for cell culture}

Mouse $\beta$-NGF (R\&D Systems, Minneapolis, USA) and K252 $\alpha$ (Sigma-Aldrich, St. Louis, USA) were prepared at a concentration of $100 \mathrm{ng} / \mathrm{ml}$ and $10 \mathrm{mM}$, as described previously [34]. We used $\alpha$-MEM culture media (Gibco, Calsbad, USA) supplemented with $0.3 \%$ (wt/vol) bovine serum albumen (BSA, Sigma-Aldrich, St. Louis, USA), 0. $23 \mathrm{mM}$ pyruvate (Sigma-Aldrich, St. Louis, USA), $75 \mathrm{mg} / \mathrm{L}$ penicillin $\mathrm{G}$ and $50 \mathrm{mg} / \mathrm{L}$ streptomycin sulfate (Gibco, Calsbad, USA).

Isolation and collection of COCs, oocytectomized cumulus cells (OOX-cumulus cells) and denuded oocytes

Follicle development was stimulated by an intraperitoneal injection of 5 IU pregnant mare serum gonadotropin (PMSG, Sigma-Aldrich, St. Louis, USA) 44-48 h before harvesting ovaries. Ovaries were removed and large antral follicles were punctured with fine hypodermic needles (number 5 grade) under a dissecting microscope. COCs and denuded oocytes were collected using a mouth-controlled, small-bore glass pipette. OOX-cumulus cells were generated by microsurgically removing oocytes from the COCs, but leaving the zonapellucida intact, as previously described [23]. In brief, each $\mathrm{COC}$ was held by negative pressure with a holding pipette, and most, or all of the oocyte, was removed by negative pressure when a lancing pipette was pushed through the COC. This lead to a spherical zonapellucida and the surrounding CCs are referred to as OOX-cumulus cells hereafter.

During the isolation progress, $10 \mathrm{mM}$ milrinone (SigmaAldrich, St. Louis, USA) was used to maintain oocytes at the germinal vesicle (GV) stage. After collection, COCs, OOX-cumulus cells and denuded oocytes were washed in culture medium three times in order to remove milrinone. These cells were then ready for further study.

\section{Cell culture and evaluation of oocyte meiotic maturation in vitro}

COCs were plated in droplets at a density of $1 \mathrm{COC} / \mu \mathrm{l}$ $[23,35]$. COCs were then cultured in medium with NGF gradients $(1,10,100$ and $1000 \mathrm{ng} / \mathrm{ml})$ for $18 \mathrm{~h}$, or in medium containing $100 \mathrm{ng} / \mathrm{ml}$ of NGF for 10,12 , and $18 \mathrm{~h}$ with or without $10 \mu \mathrm{M} \mathrm{K} 252 \alpha$. The proportion of first polar body (PB1) was calculated by removing CCs under a stereomicroscope and evaluating the status of oocyte meiotic maturation.

COCs, OOX-cumulus cells, denuded oocytes and OOX-cumulus cells co-cultured with denuded oocytes $[31,36]$ (referred as "OOX + DO") were cultured separately with or without NGF for $18 \mathrm{~h}$, then CCs and oocytes were collected for target gene analysis.

To examine whether NGF-treated CCs inhibit oocyte meiotic maturation, OOX-cumulus cells were first stimulated with NGF for $24 \mathrm{~h}$ ( 1 or 2 OOX-cumulus cells per microliter of medium) and then removed [37]. Denuded oocytes were then added into the supernatants at a concentration of $1 \mathrm{DO} / \mu \mathrm{l}$ for $18 \mathrm{~h}$ and then collected for target gene analysis.

\section{Immunofluorescence}

Ovaries were harvested as described above and $20-\mu \mathrm{m}$ cryosections were prepared and blocked with 5\% BSA for $1 \mathrm{~h}$, incubated with rabbit anti-neurotrophic receptor tyrosine kinase 1 (NTRK1) monoclonal antibody (Abcam, Cambridge, UK) overnight at $4{ }^{\circ} \mathrm{C}$, and then labeled with Alexa Fluor 549 donkey anti-rabbit antibody (Jackson Immuno Research, West Grove, USA). Sections were then stained with DAPI (Solarbio, Beijing, China) before mounting with Gold Anti-fade Reagent (Invitrogen, Calsbad, USA). Images were then acquired with an LSM710 (Carl Zeiss, Milano, Italy). 
Table 1 Primers for real-time qPCR

\begin{tabular}{|c|c|c|c|}
\hline Gene name & GenBank accession number & Sequences of forward $(F)$ and reverse $(R)$ primers & Amplification size (bp) \\
\hline$m-P f k p$ & NM_019703 & $\begin{array}{l}\text { F: 5'-GCCGTGAAACTCCGAGGAA-3' } \\
\text { R: 5'-GTTGCTCTTGACAATCTTCTCATCAG-3' }\end{array}$ & 96 \\
\hline m-Ldha & NM_001136069.2 & $\begin{array}{l}\text { F: 5'-TGTGGCAGACTTGGCTGAGA-3' } \\
\text { R: 5'-CTGAGGAAGACATCCTCATTGATTC-3' }\end{array}$ & 105 \\
\hline$m-G d f 9$ & NM_008110.2 & $\begin{array}{l}\text { F: 5'-TCACCTCTACAATACCGTCCGG-3' } \\
\text { R: 5'-GAGCAAGTGTTCCATGGCAGTC-3' }\end{array}$ & 139 \\
\hline$m-B m p 15$ & NM_009757.4 & $\begin{array}{l}\text { F: 5'-GCACGATTGGAGCGAAAATG-3' } \\
\text { R: 5'-CGTACGCTACCTGGTITGATGC-3' }\end{array}$ & 123 \\
\hline$m-F g f 8$ & NM_010205.2 & $\begin{array}{l}\text { F: 5'-CAGGTCTCTACATCTGCATGAACAA-3' } \\
\text { R: 5'-TCTCCAGCACGATCTCTGTGAATA-3' }\end{array}$ & 96 \\
\hline m-Actin & NM_007393.5 & $\begin{array}{l}\text { F:5'-TGGCTCCTAGCACCATGAA-3' } \\
\text { R: 5'-CTCAGTAACAGTCCGCCTAGAAGCA-3' }\end{array}$ & 186 \\
\hline h-PFKP & NM_002627.4 & $\begin{array}{l}\text { F: 5'-AGGCGATGGACGAGAGGAGAT-3' } \\
\text { R: 5'-TGATGGCAAGTCGCTTGTAG-3' }\end{array}$ & 93 \\
\hline$h-L D H A$ & NM_001165414.1 & $\begin{array}{l}\text { F: 5'-TGCACCCAGATTTAGGGACTGAT-3' } \\
\text { R: 5'-CCCAGGATGTGTAGCCTITGAG-3' }\end{array}$ & 111 \\
\hline$h-A C T I N$ & NM_001101.3 & $\begin{array}{l}\text { F: 5'-TGGCACCCAGCACAATGAA-3' } \\
\text { R: 5'-CTAAGTCATAGTCCGCCTAGAAGCA-3' }\end{array}$ & 186 \\
\hline
\end{tabular}

$m$ - mouse, $h$ - human, $b p$ base pair

\section{Real-time qPCR}

RNA was extracted using the Dynabeads mRNA DIRECT micro kit (Ambion, Carlsbad, USA). Real-time qPCR was performed using the PrimeScript RT reagent kit (Takara, Shiga, Japan) and the SYBR Premix Ex Taq II Kit (Takara, Shiga, Japan). Primers used for real-time qPCR were selected according to previous reports [31, 34, 38] and listed in Table 1 . The specificity of these primers were validated by dissociation curve analysis. Target genes were normalized to actin gene. Data were analyzed using the comparative $2^{-\triangle \Delta C t}$ method [34].

\section{Statistical analysis}

Statistical analysis was performed using the Student's $t$ test. $P<0.05$ was considered to be statistically significant ( $\left.{ }^{*} P<0.05 ;{ }^{* *} P<001 ;{ }^{* * *} P<0.001\right)$.

\section{Results}

Excessive NGF is present in the follicular fluid of PCOS patients and inhibits oocyte maturation in vitro

We firstly detected NGF content in follicular fluid of Chinese PCOS patients. The clinical characteristics of PCOS and non-PCOS patients were shown in Table 2. The concentration of NGF in follicular fluid was significantly higher

Table 2 Clinical characteristics of PCOS and non-PCOS patients

\begin{tabular}{|c|c|c|c|}
\hline & PCOS & non-PCOS & $P$ value \\
\hline Total $(n)$ & 9 & 13 & \\
\hline IVF-ET (n) & 4 & 4 & \\
\hline ICSI-ET (n) & 5 & 9 & \\
\hline Age (year) & $29.53 \pm 5.61$ & $28.22 \pm 2.42$ & 0.46 \\
\hline BMI & $24.36 \pm 3.24$ & $22.63 \pm 2.46$ & $<0.001$ \\
\hline $\mathrm{LH}(\mathrm{IU} / \mathrm{ml})$ & $10.47 \pm 4.62$ & $6.23 \pm 3.29$ & $<0.0001$ \\
\hline FSH (IU/ml) & $5.27 \pm 1.41$ & $7.58 \pm 2.13$ & $<0.0001$ \\
\hline Testosterone (ng/dl) & $52.62 \pm 18.74$ & $26.37 \pm 11.92$ & $<0.0001$ \\
\hline Antral follicle count (n) & $34.51 \pm 13.08$ & $16.24 \pm 5.36$ & $<0.0001$ \\
\hline Starting Gn dose (IU) & $152.81 \pm 32.24$ & $178.77 \pm 36.69$ & 0.0013 \\
\hline Gn stimulation duration (day) & $12.43 \pm 3.26$ & $10.37 \pm 2.17$ & 0.0026 \\
\hline Total Gn administrated (IU) & $1899.43 \pm 579.52$ & $1933.46 \pm 627.41$ & 0.54 \\
\hline E2 level on hCG day (pg/ml) & $5768.27 \pm 2843.32$ & $4689.66 \pm 1895.24$ & 0.005 \\
\hline Follicles $\geq 14$ mm (n) & $16.43 \pm 4.15$ & $12.46 \pm 3.53$ & $<0.0001$ \\
\hline Oocytes retrieved $(n)$ & $18.62 \pm 8.05$ & $13.88 \pm 4.95$ & $<0.0001$ \\
\hline
\end{tabular}



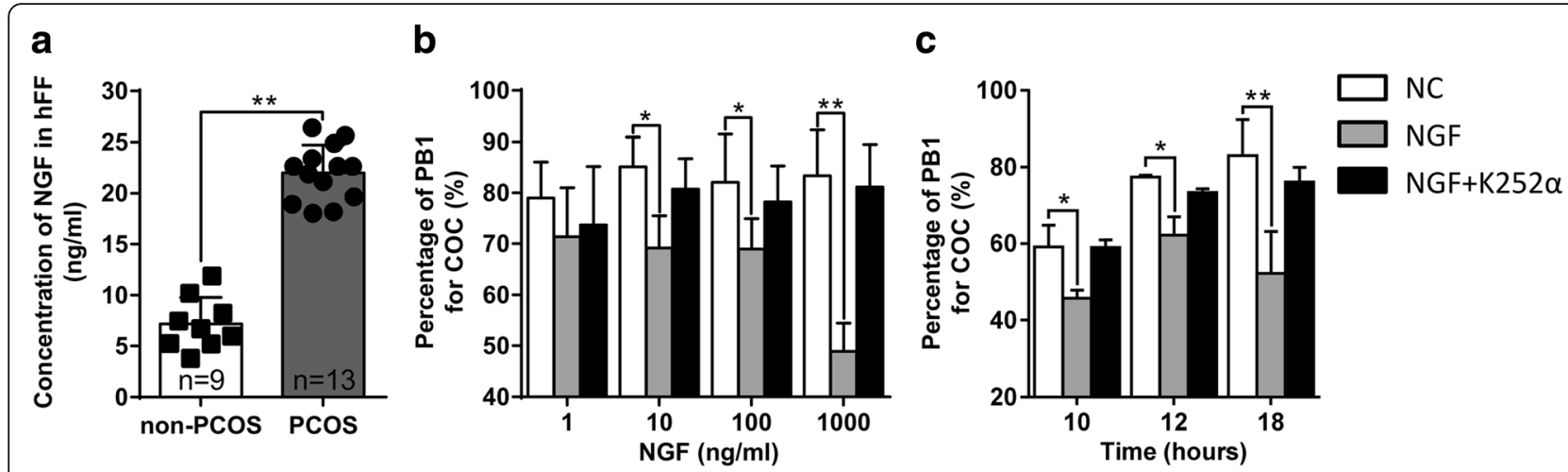

Fig. 1 Excessive NGF inhibited mouse oocyte maturation. a Excessive NGF in the follicular fluid of Chinese PCOS patients. Concentration of NGF in human follicular fluid (hFF) of Chinese non-PCOS patients $(n=9)$ and PCOS patients $(n=13)$ was determined by ELISA. b-c COCs were cultured

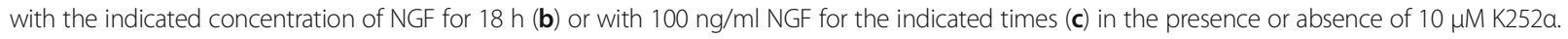
The proportion of PB1 extrusion was then calculated. The number of COCs for each group was $\geq 35$. Representative data are presented as mean \pm SEM. ${ }^{*}, p<0.05 ;{ }^{* *}, p<0.01$

in the PCOS group $(22 \pm 2.63 \mathrm{ng} / \mathrm{ml}, n=13)$ than that in the non-PCOS group $(7.18 \pm 2.42 \mathrm{ng} / \mathrm{ml}, n=9)$ (Fig. 1a).

To observe the effect of NGF on oocyte maturation, mouse COCs from antral follicles were cultured with different concentrations of NGF. This showed that 10 and $100 \mathrm{ng} / \mathrm{ml}$ of NGF significantly suppressed PB1 extrusion, a hallmark of oocyte meiotic maturation, and that $1000 \mathrm{ng} / \mathrm{ml}$ of NGF had a stronger suppressive effect (Fig. 1b). Taking an overall consideration of both NGF concentrations in the follicular fluid of PCOS patients and their inhibitory effect in vitro, we chose $100 \mathrm{ng} / \mathrm{ml}$ as an excessive concentration of NGF that mimics excessive levels of NGF in the follicular fluid of PCOS patients and used this concentration in our subsequent experiments. The inhibitory effect of $100 \mathrm{ng} / \mathrm{ml}$ NGF on PB1 extrusion was observed at 10, 12, and $18 \mathrm{~h}$ after NGF treatment (Fig. 1c), indicating that the inhibitory effect existed throughout the progression of meiosis I.
NTRK1, the high affinity receptor for NGF, is expressed on CCs in antral follicles

To explore the mechanisms underlying the inhibitory effect of NGF, we analyzed the cellular expression of NTRK1, the high affinity receptor for NGF previously known as TrkA [1]. Intense expression of NTRK1 was detected on the surface of CCs in antral follicles (Fig. 2). Notably, expression of NTRK1 was not detected on oocytes in antral follicles (Fig. 2). Thus, in our in vitro cultured COCs, NTRK1 was exclusively expressed by CCs. To validate the role of NTRK1, we utilized K252 $\alpha$, the phosphorylation inhibitor of NTRK1, during in vitro culture of COCs. The addition of $\mathrm{K} 252 \alpha$ into the culture medium of COCs abolished the suppressive effect of NGF, indicating that the inhibitory effect was mediated by NTRK1. Collectively, these results indicate that excessive NGF inhibit the meiotic maturation of oocytes in COCs via its high affinity receptor NTRK1 which is expressed on CCs.
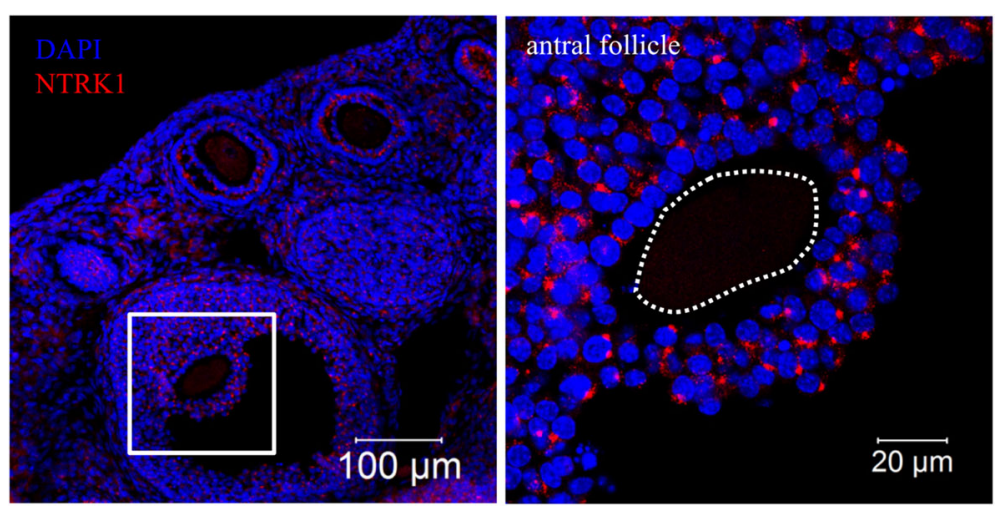

Fig. 2 Cellular localization of NTRK1 at the antral follicle stage. Left, representative overview confocal image of NTRK1 staining. Right, magnified image of an antral follicle. Dotted line shows the position of the oocyte. Representative images of three independent experiments are shown 

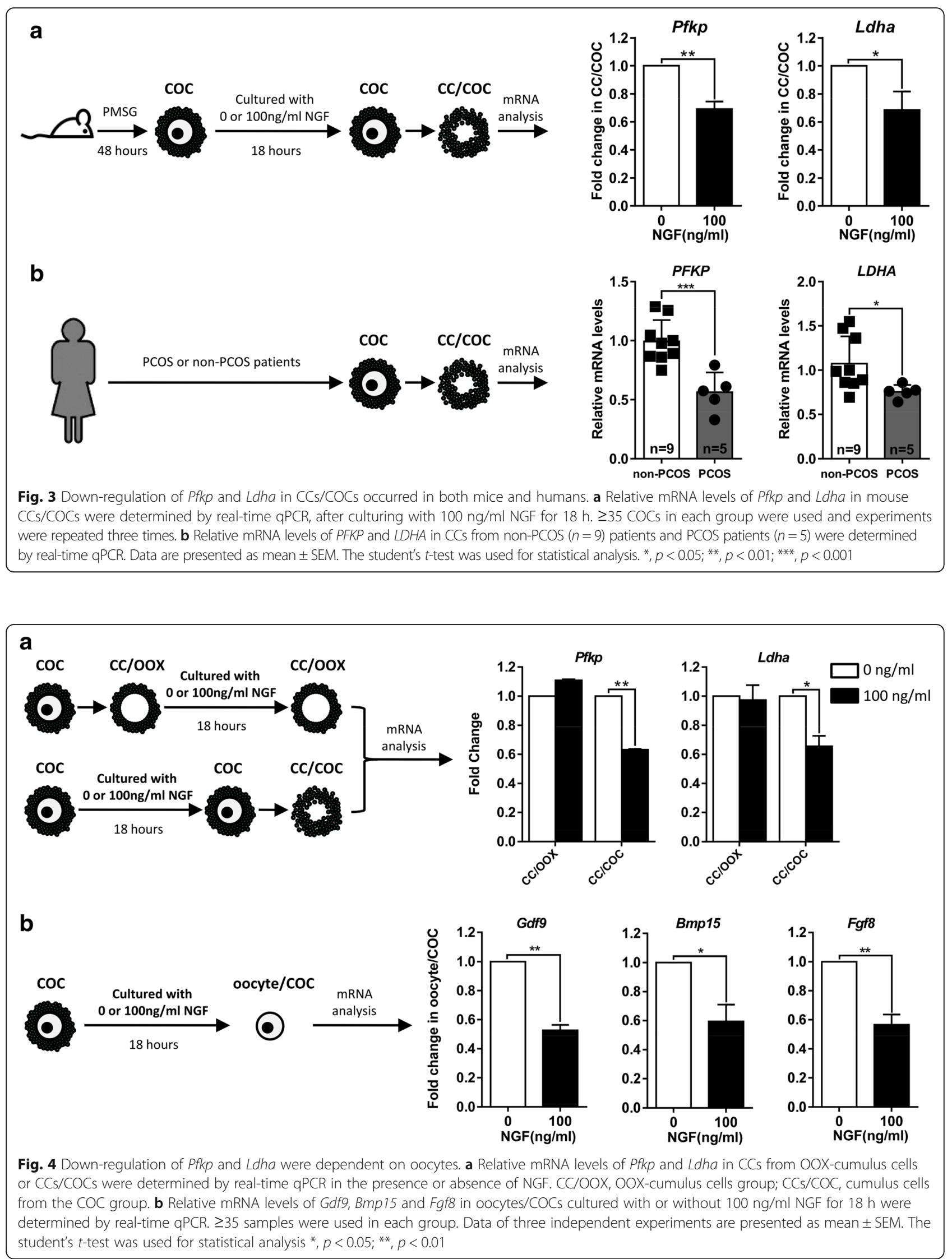
The glycolysis of CCs from COCs is down-regulated in the presence of excessive NGF in both mice and humans Because the inhibitory effect of excessive NGF was mediated by NTRK1 expressed on CCs and because glycolysis in the CCs produces the pyruvate that is essential for oocyte maturation, we next analyzed the effect of NGF on glycolysis in CCs. Mouse antral follicle-derived COCs were stimulated by excessive NGF and then CCs were collected to examine the expression of $P f k p$ and $L d h a$, genes encoding rate-limiting enzymes of glycolysis [31]; this allowed us to evaluate the process of glycolysis. The mRNA expression levels of Pfkp and Ldha decreased significantly in the presence of excessive NGF (Fig. 3a). Similar to the results in mice, the mRNA expression levels of PFKP and $L D H A$ in CCs from PCOS patients were lower than that in non-PCOS patients (Fig. 3b). PFKP was downregulated by 2 -fold (Fig. $3 \mathrm{~b}$, left) while $L D H A$ was reduced by 1.5 -fold (Fig. 3b, right). Collectively, this data suggests that in the presence of excessive NGF, the expression levels of glycolytic rate-limiting enzymes in the $\mathrm{CCs}$ of $\mathrm{COCs}$ were down-regulated in both mice and humans.
NGF-induced down-regulation of glycolysis in CCs is dependent on oocytes

To observe the direct effect of excessive NGF on CCs, OOX-cumulus cells were treated with excessive NGF but no significant change of mRNA levels of $P f k p$ and Ldha was observed (Fig. 4a). Taking into account the significant inhibition of NGF on glycolysis in CCs from cultured COCs (Fig. 4b), it can be concluded that the inhibitory effect of NGF on glycolysis in CCs was dependent on oocytes. Consistent with the downregulated glycolysis in CCs, the mRNA expression levels of Gdf9, Bmp15 and Fgf8, which are three wellcharacterized ODPFs, were decreased in oocytes from COCs cultured with excessive levels of NGF (Fig. 4b). Levels of Gdf9 and Fgf8 were reduced by 2-fold and Bmp 15 was reduced by 1.5 -fold. Therefore, the reduced production of ODPFs in oocytes might be responsible for the down-regulation of glycolysis in CCs.

\section{NGF-stimulated CCs inhibited the production of ODPFs in} oocytes

We further explored how excessive NGF caused a reduced production of ODPFs. As NTRK1 is expressed on CCs, but
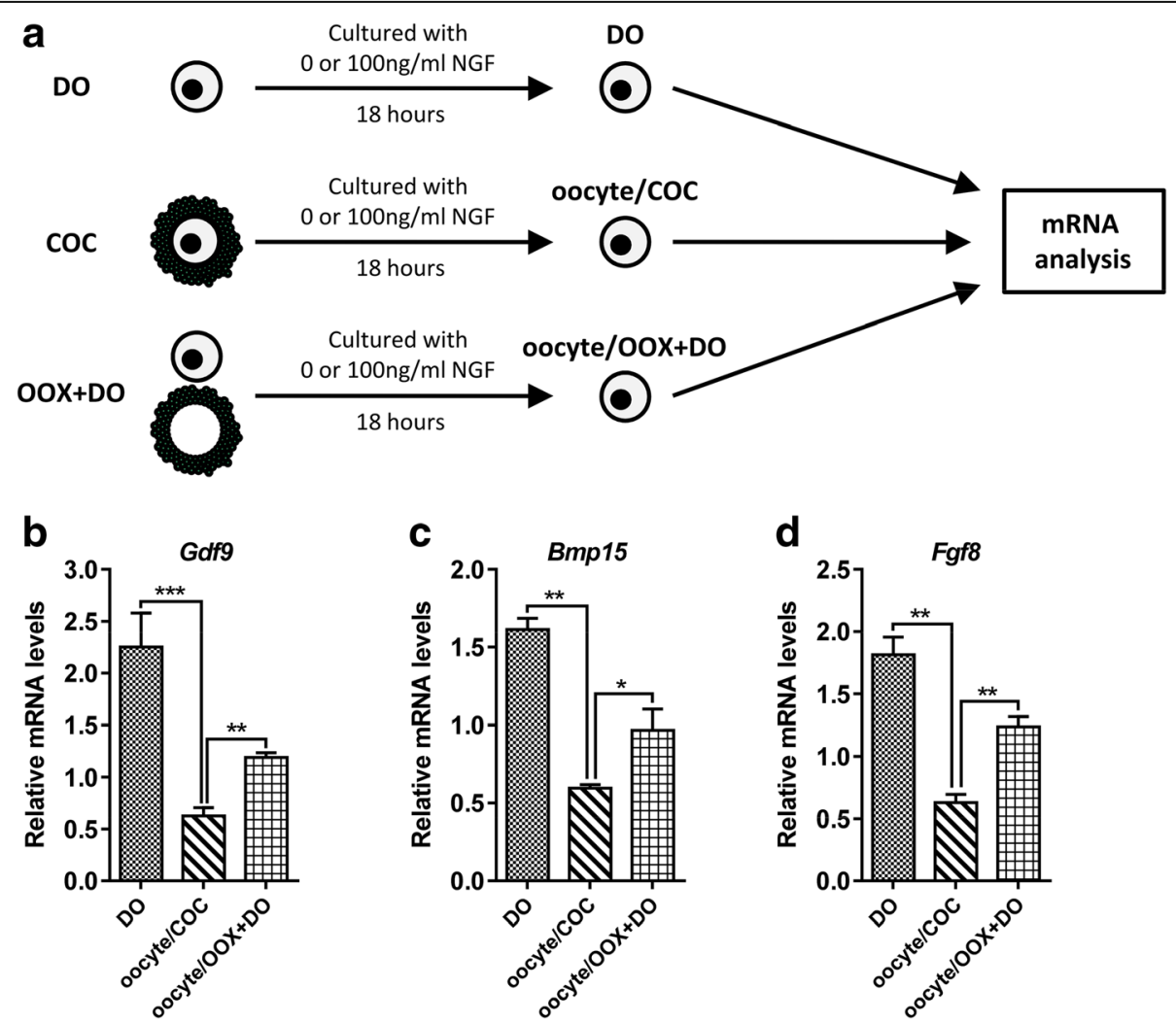

Fig. 5 Decrease of ODPFs in oocytes was mediated by CCs. a Schematic diagram of the culturing system. $\mathbf{b}$-d The relative mRNA levels of Gdf9 (b), Bmp15 (c) and Fgf8 (d) in oocytes respectively from DOs, COCs and "OOX + DO" group were determined by real-time q-PCR cultured in medium with $100 \mathrm{ng} / \mathrm{ml}$ NGF for $18 \mathrm{~h}$. DO, denuded oocyte; oocyte/COC, oocytes from COC group; oocyte/OOX + DO, oocytes from the co-cultured OOX-cumulus cells and denuded oocytes group. $\geq 35$ oocytes were used for RNA extraction in each group. Experiments were repeated at least three times independently. Data are presented as mean \pm SEM. Student's two-tailed t-test was used for statistical analysis ${ }^{*}, p<0.05 ;{ }^{* *}, p<0.01,{ }^{* *}, p<0.001$ 
not on oocytes, the reduction in ODPF production in oocytes might be caused by NGF-stimulated CCs. Indeed, when stimulated with excessive NGF, oocytes cultured in the presence of CCs, either in the form of COCs or separately added OOX-cumulus cells to cultured denuded oocytes (referred as "OOX $+\mathrm{DO}$ "), expressed less ODPFs than denuded oocytes cultured alone (Fig. 5). These results also implied that the inhibitory effect upon the production of ODPFs was mediated by soluble factors derived from CCs. To validate this, OOX-cumulus cells were stimulated with excessive NGF for $18 \mathrm{~h}$, and the culture supernatant was collected to culture denuded oocytes (Fig. 6a). The expression of ODPFs in denuded oocytes cultured in the supernatant of NGF-stimulated OOX-cumulus cells decreased significantly (Fig. 6b). The inhibitory effect of the supernatant was correlated with the concentration of cultured OOX-cumulus cells. The supernatant of OOXcumulus cells cultured at a concentration of 2 OOXs $/ \mu \mathrm{l} \mathrm{ex-}$ hibited a stronger inhibitory effect than that cultured at a concentration of $1 \mathrm{OOX} / \mu \mathrm{l}$. Overall, CCs stimulated by excessive NGF inhibited the production of ODPFs in oocytes.

\section{Discussion}

Previous studies have reported that NGF content is significantly increased in the ovarian follicular fluid of
PCOS patients from Germany, Italy and Canada [13, 15, 17]. In the present study, we also observed excessive levels of NGF in the follicular fluid of Chinese PCOS patients. The increase of NGF in follicular fluid is associated with lower ovarian responses in aged women [39]. Studies in the rat have shown that the abnormally elevated production of NGF within the ovary increases androgen secretion, disrupts the estrous cycle and is sufficient to initiate several of the structural and functional alterations associated with the development of follicular cysts [40]. In the present study, by treating in vitro cultured COCs with excessive concentrations of NGF, we revealed an inhibitory role of excessive NGF on oocyte maturation. Furthermore, by using well-established models of OOXcumulus cells, we proved that bidirectional communication between oocytes and CCs mediated the inhibitory function of NGF. Thus, excessive NGF inhibited oocyte maturation in a bidirectional communication dependent manner, indicating a potential pathogenic role of NGF in the progression of PCOS.

According to previous reports, the concentration of NGF in the follicular fluid of PCOS patients varies over a large range across different studies [13, 15, 17]. For example, Dissen et al. reported that the median concentration of NGF in 11 PCOS patients was $5-7 \mathrm{ng} / \mathrm{ml}$ [13].

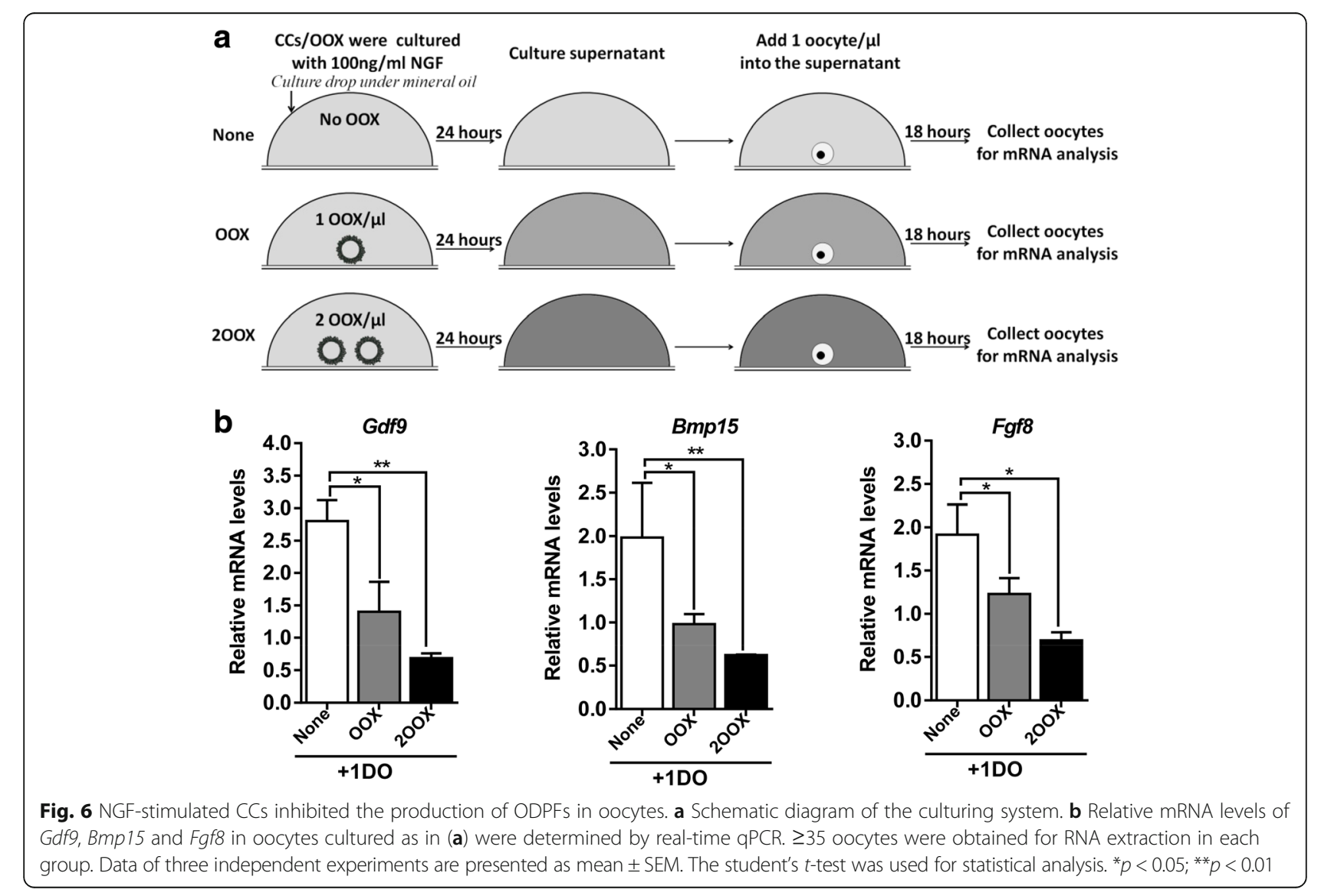


Sadeu et al. further reported that NGF concentration in 16 PCOS patients ranged from 58.5 to $375 \mathrm{ng} / \mathrm{ml}$ [17]. In another study, Gulino et al. reported that the mean concentration of NGF in 32 PCOS patients was 2023.30 $\pm 587.09 \mathrm{pg} / \mathrm{mL}$ [15]. In our present study, the concentration of NGF in follicular fluid ranged from 18 to $26 \mathrm{ng} / \mathrm{ml}$ for the PCOS group. The differences in NGF concentrations across these studies might be caused by a variety of factors, such as geography, population, ethics and hormone levels [16]. Since the follicular fluid provides a micro-environment for oocyte development and maturation, it is valuable to explore the role of excessive NGF on oocyte maturation. In the present study, we cultured mouse COCs with different NGF concentrations, ranging from 1 to $1000 \mathrm{ng} / \mathrm{ml}$, which covered the wide range of NGF concentrations reported in previous studies. Combining NGF concentration in the follicular fluid of PCOS patients and the effect of different NGF concentrations during in-vitro culturing, $100 \mathrm{ng} / \mathrm{ml}$ of NGF was considered as a moderate concentration to mimic excessive NGF because of its significant inhibitory effect and was therefore used for subsequent experiments throughout the present study.

To explore the mechanisms underlying the inhibitory effect of NGF, we analyzed the cellular expression of NGF receptors. Two different NGF receptors have been characterized: NTRK1, the high affinity receptor for NGF and previously known as TrkA; and p75, a panspecific receptor for NT family members [1]. NTRK1 is expressed on mesenchymal cells, CCs and granulosa cells in mouse antral follicles, while p75 is only expressed on mesenchymal cells [1, 4]. Consistent with these previous reports, we detected NTRK1 expression on CCs but not on oocytes in mouse antral follicles. Thus, in our in vitro culturing system, CCs were the cells directly affected by excessive NGF. Moreover, the application of $\mathrm{K} 252 \alpha$ abolished the inhibitory effect of excessive NGF, further validating the involvement of NTRK1. In human antral follicles, the expression of NTRK1 on CCs has been reported by several studies [1, 3], while its expression in oocytes remains controversial. Nevertheless, human CCs are also capable of being stimulated by NGF in the follicular fluid. Besides the uniform expression of NTRK1 on CCs in mice and humans, decreased glycolysis, indicated by the reduced expression of Pfkp and Ldha, was observed in both mouse CCs from COCs treated with excessive levels of NGF and human CCs from the COCs of PCOS patients. As it is very difficult to obtain human samples for research, their number was low. Be that as it may, these specimens strengthened the hypothesis that was initially observed by us in mice. Since the CCs of PCOS and non-PCOS patients were collected from patients who received ICSI treatment, the corresponding oocytes were used for embryo culturing and transfer, making it impossible to analyze the expression of ODPFs in human oocytes. However, previous reports showed that the expression of GDF9 and BMP15 in oocytes from PCOS patients was reduced compared to normal ovulatory women [41, 42]. Collectively, these results suggested that the mechanisms we found in mice were also applicable for PCOS patients.

Excessive NGF inhibited the meiotic maturation of COCs cultured in vitro, suggesting that NGF can contribute to the pathogenesis of PCOS by impairing the development of COCs. Although we proved that bidirectional communication between CCs and oocytes was necessary for the inhibitory effect of excessive NGF, further experiments need to be conducted in the future. Initially, experiments treating CC/COC with GDF9, BMP15 and FGF8 in the presence of NGF should be conducted to demonstrate that ODPFs can reverse the suppression of Pfkp and Ldha by excessive NGF. Secondly, how NGF-stimulated CCs down-regulate the production of ODPFs in oocytes is still unclear. Our results suggested the existence of CC-derived inhibitory factor(s). Further identification of these inhibitory factor(s) is therefore very valuable. On the other hand, in the antral follicles of both mice and humans, mesenchymal cells are also reported to express NGF receptors [1]. Thus, mesenchymal cells are also potential target cells for excessive NGF in

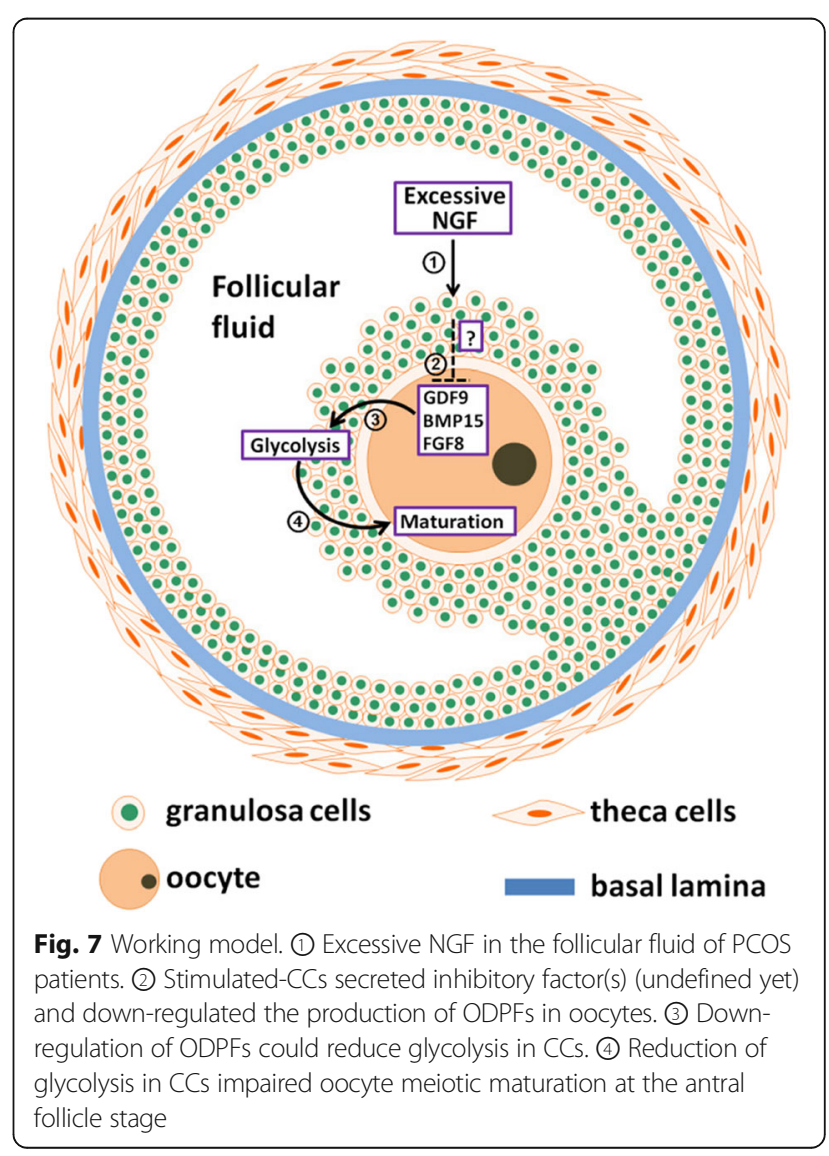


PCOS patients. Overall, it is valuable to clarify the pathogenic roles of excessive NGF and therapies targeting NGF may be beneficial for patients suffering from PCOS.

\section{Conclusions}

The present study could be summarized as Fig. 7. It demonstrates that in vitro addition of excessive NGF inhibits glycolysis in CCs and maturation of oocytes in mouse COCs and the inhibition is dependent on bidirectional communication between oocytes and CCs. Pharmacological blocking of NGF-high affinity receptor NTRK1 by K252 $\alpha$ abolished the inhibitory effect on oocyte maturation. Excessive NGF inhibits glycolysis in CCs of COCs, at least in part, by reducing the production of ODPFs in oocytes. Importantly, dysfunction of glycolysis in CCs was identified in PCOS patients with excessive NGF in the follicular fluid. Our findings revealed a pathogenic role of excessive NGF in PCOS.

\begin{abstract}
Abbreviations
BMP15: Bone morphogenetic protein 15; BSA: Bovine serum albumin; CCs: Cumulus cells; COC: Cumulus-oocyte complex; ELISA: Enzyme linked immunosorbent assay; FGF: Fibroblast growth factor; FGF8: Fibroblast growth factor 8; GDF9: Growth differentiational factors 9; ICSI: Intracytoplasmic sperm injection; IVF: In vitro fertilization; LDHA: Lactate dehydrogenase A; NGF: Nerve growth factor; NTRK1: Neurotrophic receptor tyrosine kinase 1; ODPFs: Oocyte-derived paracrine factors; OOX-cumulus cells: Oocytectomized cumulus cells; PBS: Phosphate buffered saline; PCOS: Polycystic ovary syndrome; PFKP: Phosphofructokinase, platelet; PMSG: Pregnant mare serum gonadotropin
\end{abstract}

\section{Acknowledgments}

We thank Professor Youqiang Su (Nanjing, China), Mr. Guangping Yang (Nanjing, China) for assistance on producing OOX-cumulus cells from COCs and Professor Yunhai Zhang (Hefei, China) for providing assistance with the instrumentation.

\section{Funding}

This work was supported by grants from the National Natural Science Foundation of China (Grant No. 81430027 and 81671510 to F.S.) and the National Basic Research Program of China (973 Program) (No. 2014 CB943100 to F.S.). The founding sponsors had no role in the present study.

\section{Availability of data and materials}

Not applicable.

\begin{abstract}
Authors' contributions
$Y Z$ designed and performed the experiments and wrote the paper; FR revised the paper; GY, YW, and XS supplied reagents and materials. FS designed and supervised the experiments and wrote the manuscript. All authors read and approved the final manuscript.
\end{abstract}

\section{Ethics approval and consent to participate}

The study was approved by the Institutional Review Board of the University of Science and Technology of China on the 18th May 2012 (Reference: USTCACUC1201054).

Written informed consent was obtained from all patients and the study was approved by the Ethics Review Board of the First Affiliated Hospital of Zhengzhou University on 20 ${ }^{\text {th }}$ November 2014 (Reference: 2014-LW-1217).

\section{Consent for publication}

Not applicable.

\section{Competing interests}

The authors declare that they have no competing interests.

\section{Publisher's Note}

Springer Nature remains neutral with regard to jurisdictional claims in published maps and institutional affiliations.

\section{Author details}

${ }^{1}$ School of Life Sciences, University of Science and Technology of China, Hefei, Anhui, People's Republic of China. ${ }^{2}$ Hefei National Laboratory for Physical Sciences at Microscale, Hefei, Anhui, People's Republic of China. ${ }^{3}$ Reproductive Medical Center, The First Affiliated Hospital of Zhengzhou University, Zhengzhou, Henan, People's Republic of China.

Received: 29 November 2017 Accepted: 15 March 2018

Published online: 27 March 2018

\section{References}

1. Streiter S, Fisch B, Sabbah B, Ao A, Abir R. The importance of neuronal growth factors in the ovary. Mol Hum Reprod. 2016;22(1):3-17.

2. Dissen GA, Romero C, Hirshfield AN, Ojeda SR. Nerve growth factor is required for early follicular development in the mammalian ovary. Endocrinology. 2001;142(5):2078-86.

3. Abir R, Fishc B, Jin S, Barnnet M, Ben-Haroush A, Felz C, Kessler-Icekson G, Feldberg D, Nitke $S, A o$ A. Presence of NGF and its receptors in ovaries from human fetuses and adults. Mol Hum Reprod. 2005;11(4):229-36.

4. Dissen GA, Romero C, Paredes A, Ojeda SR. Neurotrophic control of ovarian development. Microsc Res Tech. 2002;59(6):509-15.

5. Mayerhofer A, Dissen GA, Parrott JA, Hill DF, Mayerhofer D, Garfield RE, Costa ME, Skinner MK, Ojeda SR. Involvement of nerve growth factor in the ovulatory cascade: trkA receptor activation inhibits gap junctional communication between thecal cells. Endocrinology. 1996;137(12):5662-70.

6. Chaves RN, Alves AMCV, Duarte ABG, Araujo VR, Celestino JJH, Matos MHT, Lopes CAP, Campello CC, Name KPO, Bao SN, et al. Nerve growth factor promotes the survival of goat preantral follicles cultured in vitro. Cells Tissues Organs. 2010;192(4):272-82.

7. Naicy T, Venkatachalapathy RT, Aravindakshan TV, Radhika G, Raghavan KC, Mini M, Shyama K. Nerve Growth Factor gene ovarian expression, polymorphism identification, and association with litter size in goats. Theriogenology. 2016;86(9):2172-2178.e3.

8. Naicy T, Venkatachalapathy RT, Aravindakshan TV, Raghavan KC, Mini M, Shyama K. Relative abundance of tissue mRNA and association of the single nucleotide polymorphism of the goat NGF gene with prolificacy. Anim Reprod Sci. 2016;173:42-8.

9. Linher-Melville K, Li J. The roles of glial cell line-derived neurotrophic factor, brain-derived neurotrophic factor and nerve growth factor during the final stage of folliculogenesis: a focus on oocyte maturation. Reproduction. 2013; 145(2):R43-54.

10. Barboni B, Mattioli M, Gioia L, Turriani M, Capacchietti G, Berardinelli P, Bernabo N. Preovulatory rise of NGF in ovine follicular fluid: possible involvement in the control of oocyte maturation. Microsc Res Tech. 2002:59(6):516-21.

11. Crispo M, dos Santos-Neto PC, Vilariño M, Mulet AP, De León A, Barbeito L, Menchaca A. Nerve growth factor influences cleavage rate and embryo development in sheep. J Anim Sci. 2016;94(10):4447-51.

12. Papp AB, Somfai $T$, Tartaglione $M$, Varga $E, J C$ G. The effect of nerve growth factor on nuclear progression of porcine oocytes during in vitro maturation and embryo development. Acta Vet Hung. 2005;53(1):91-101.

13. Dissen GA, Garcia-Rudaz C, Paredes A, Mayer C, Mayerhofer A, Ojeda SR. Excessive ovarian production of nerve growth factor facilitates development of cystic ovarian morphology in mice and is a feature of polycystic ovarian syndrome in humans. Endocrinology. 2009;150(6):2906-14.

14. Wilson JL, Chen W, Dissen GA, Ojeda S, Cowley MA, Garcia-Rudaz C, Enriori PJ. Excess of nerve growth factor in the ovary causes a polycystic ovary-like syndrome in mice, which closely resembles both reproductive and metabolic aspects of the human syndrome. Endocrinology. 2014;155(11):4494-506.

15. Gulino FA, Giuffrida E, Leonardi E, Marilli I, Palumbo MA. Intrafollicular nerve growth factor (NGF) concentration in patients with polycystic ovarian syndrome case-control study. Minerva Ginecol. 2016;68(2):110-6.

16. Qiao J, Feng HL. Extra- and intra-ovarian factors in polycystic ovary syndrome: impact on oocyte maturation and embryo developmental competence. Hum Reprod Update. 2011;17(1):17-33.

17. Sadeu JC, Doedée A, Neal MS, Hughes EG, Foster WG. Neurotrophins (BDNF and NGF) in follicular fluid of women with different infertility diagnoses. Reprod BioMed Online. 2012;24(2):174-9. 
18. Dumesic DA, Abbott DH. Implications of polycystic ovary syndrome on oocyte development. Semin Reprod Med. 2008;26(1):53-61.

19. Wood JR, Dumesic DA, Abbott DH, Strauss JF 3rd. Molecular abnormalities in oocytes from women with polycystic ovary syndrome revealed by microarray analysis. J Clin Endocrinol Metab. 2007;92(2):705-13.

20. Heijnen E, Eijkemans MJC, Hughes EG, Laven JSE, Macklon NS, Fauser B. A meta-analysis of outcomes of conventional IVF in women with polycystic ovary syndrome. Hum Reprod Update. 2006;12(1):13-21.

21. Hussein TS, Thompson JG, Gilchrist RB. Oocyte-secreted factors enhance oocyte developmental competence. Dev Biol. 2006;296(2):514-21.

22. Eppig JJ. Oocyte control of ovarian follicular development and function in mammals. Reproduction. 2001;122:829-38.

23. Su Y-Q, Wu X, O'Brien MJ, Pendola FL, Denegre JN, Matzuk MM, Eppig JJ. Synergistic roles of BMP15 and GDF9 in the development and function of the oocyte-cumulus cell complex in mice: genetic evidence for an oocytegranulosa cell regulatory loop. Dev Biol. 2004;276(1):64-73.

24. Matzuk MM, Burns KH, Viveiros MM, Eppig JJ. Intercellular communication in the mammalian ovary: oocytes carry the conversation. Science. 2002; 296(5576):2178-80.

25. Biggers JD, Whittingham DG, Donahue RP. The pattern of energy metabolism in the mouse oocyte and zygote. Proc Natl Acad Sci U S A. 1967;58:560-7.

26. Leese HJ, Barton AM. Production of pyruvate by isolated mouse cumulus cells. J Exp Zool A Ecol Genet Physiol. 1985;234(2):231-6.

27. Sugiura K, Pendola FL, Eppig JJ. Oocyte control of metabolic cooperativity between oocytes and companion granulosa cells: energy metabolism. Dev Biol. 2005;279(1):20-30

28. Valve E, Penttilä TL, Paranko J, Härkönen P. FGF-8 is expressed during specific phases of rodent oocyte and spermatogonium development. Biochem Biophys Res Commun. 1997;232(1):173-7.

29. Elvin JA, Clark AT, Wang P, Wolfman NM, Matzuk MM. Paracrine actions of growth differentiation factor-9 in the mammalian ovary. Mol Endocrinol. 1999;13:1035-48.

30. Shimasaki S, Kelly Moore R, Otsuka F, Erickson GF. The bone morphogenetic protein system in mammalian reproduction. Endocr Rev. 2004;25(1):72-101.

31. Sugiura K, Su YQ, Diaz FJ, Pangas SA, Sharma S, Wigglesworth K, O'Brien MJ, Matzuk MM, Shimasaki S, Eppig JJ. Oocyte-derived BMP15 and FGFS cooperate to promote glycolysis in cumulus cells. Development. 2007 134(14):2593-603.

32. Wei D, Xie J, Yin B, Hao H, Song X, Liu Q, Zhang C, Sun Y. Significantly lengthened telomere in granulosa cells from women with polycystic ovarian syndrome (PCOS). J Assist Reprod Genet. 2017;34(7):861-8.

33. Zettler C, Bridges DC, Zhou XF, Rush RA. Detection of increased tissue concentrations of nerve growth factor with an improved extraction procedure. J Neurosci Res. 1996;46(5):581-94.

34. Wang $Y$, Liang $N$, Yao G, Tian $H$, Zhai $Y$, Yin $Y$, Sun F. Knockdown of TrkA in cumulus oocyte complexes (COCs) inhibits EGF-induced cumulus expansion by down-regulation of IL-6. Mol Cell Endocrinol. 2014;382(2):804-13.

35. Su Y-Q, Denegre JM, Wigglesworth K, Pendola FL, O'Brien MJ, Eppig JJ. Oocyte-dependent activation of mitogen-activated protein kinase (ERK1/2) in cumulus cells is required for the maturation of the mouse oocytecumulus cell complex. Dev Biol. 2003;263(1):126-38.

36. Zhang M, Su YQ, Sugiura K, Xia G, Eppig JJ. Granulosa cell ligand NPPC and its receptor NPR2 maintain meiotic arrest in mouse oocytes. Science. 2010; 330:366-9.

37. Wigglesworth K, Lee KB, O'Brien MJ, Peng J, Matzuk MM, Eppig JJ. Bidirectional communication between oocytes and ovarian follicular somatic cells is required for meiotic arrest of mammalian oocytes. Proc Natl Acad Sci. 2013;110(39):E3723-9.

38. Monti M, Redi C. Ologenesis specific genes (Nobox, Oct4, Bmp15, Gdf9, Oogenesin 1 and Oogenesin2) are differentially expressed during natural and gonadotropin-induced mouse follicular development. Mol Reprod Dev. 2009;76(10):994-1003.

39. Palumbo MA, Giuffrida E, Gulino FA, Leonardi E, Cantarella G, Bernardini R. Nerve growth factor (NGF) levels in follicular fluid of infertile patients undergoing to in vitro fertilization (IVF) cycle. Gynecol Endocrinol. 2013; 29(11):1002-4

40. Dissen GA, Lara HE, Leyton V, Paredes A, Hill DF, Costa ME, Martinez-Serrano A, Ojeda SR. Intraovarian excess of nerve growth factor increases androgen secretion and disrupts estrous cyclicity in the rat. Endocrinology. 2000; 141(3):1073-82.
41. Wei LN, Huang R, Li LL, Fang C, Li Y, Liang XY. Reduced and delayed expression of GDF9 and BMP15 in ovarian tissues from women with polycystic ovary syndrome. J Assist Reprod Genet. 2014;31(11):1483-90.

42. Teixeira de Resende LO, Vireque AA, Santana LF, Moreno DA, de Sa Rosa e Silva AC, Ferriani RA, Scrideli CA, Reis RM. Single-cell expression analysis of BMP15 and GDF9 in mature oocytes and BMPR2 in cumulus cells of women with polycystic ovary syndrome undergoing controlled ovarian hyperstimulation. J Assist Reprod Genet. 2012;29(10):1057-65.

\section{Submit your next manuscript to BioMed Central and we will help you at every step:}

- We accept pre-submission inquiries

- Our selector tool helps you to find the most relevant journal

- We provide round the clock customer support

- Convenient online submission

- Thorough peer review

- Inclusion in PubMed and all major indexing services

- Maximum visibility for your research

Submit your manuscript at www.biomedcentral.com/submit
Biomed Central 